\title{
World Journal of Emergency

\section{Complicated diverticular disease of the colon, do we need to change the classical approach, a retrospective study of 110 patients in southeast England}

\author{
Abdulzahra Hussain*1,2, Hind Mahmood ${ }^{1}$, Gokulakkrishna Subhas ${ }^{1}$ and \\ Shamsi EL-Hasani ${ }^{1}$
}

Address: ${ }^{1}$ Department of general surgery, Princess Royal University Hospital, Kent, UK and ${ }^{2}$ General surgery department, Farnborough common, Orrington, BR6 8ND, Kent, UK

Email: Abdulzahra Hussain* - azahrahussain@yahoo.com; Hind Mahmood - hindkass@yahoo.com;

Gokulakkrishna Subhas -drsgokul@yahoo.com; Shamsi EL-Hasani - shamsi.el-hasani@bromleyhospitals.nhs.uk

* Corresponding author

Published: 24 January 2008

World Journal of Emergency Surgery 2008, 3:5 doi:10.1186/1749-7922-3-5

This article is available from: http://www.wjes.org/content/3/I/5

(C) 2008 Hussain et al; licensee BioMed Central Ltd.

This is an Open Access article distributed under the terms of the Creative Commons Attribution License (http://creativecommons.org/licenses/by/2.0), which permits unrestricted use, distribution, and reproduction in any medium, provided the original work is properly cited.

\begin{abstract}
Background: Complicated diverticular disease of the colon imposes a serious risk to patient's life, challenge to surgeons and has cost implications for health authority. The aim of this study is to evaluate the management outcome of complicated colonic diverticular disease in a district hospital and to explore the current strategies of treatment.
\end{abstract}

Methods: This is a retrospective study of all patients who were admitted to the surgical ward between May 2002 and November 2006 with a diagnosis of complicated diverticular disease. A proforma of patients' details, admission date, ITU admission, management outcomes and the follow up were recorded from the patients case notes and analyzed. The mean follow-up was 34 months (range 6-60 months)

Results: The mean age of patients was 72.7 years (range 39-87 years). Thirty-one men (28.18\%) and Seventy-nine women (71.8I\%) were included in this study. Male: female ratio was I:2.5.

Sixty-eight percent of patients had one or more co-morbidities. Forty-one patients (37.27\%) had two or more episodes of diverticulitis while $41.8 \%$ of them had no history of diverticular disease.

Eighty-six percent of patients presented with acute abdominal pain while bleeding per rectum was the main presentation in $14 \%$. Constipation and erratic bowel habit were the commonest chronic symptoms in patients with history of diverticular disease. Generalized tenderness was reported in $64.28 \%$ while $35.71 \%$ have left iliac fossa tenderness. Leukocytosis was reported in 58 patients (52.72\%).

The mean time from the admission until the start of operative intervention was 20.57 hours (range 4-96 hours). Perforation was confirmed in 59.52\%. Mortality was $10.90 \%$. Another 4 (3.63\%) died during follow up for other reasons.

Conclusion: Complicated diverticular disease carries significant morbidity and mortality. These influenced by patient-related factors. Because of high mortality and morbidities, we suggest the need to target a specific group of patients for prophylactic resection. 


\section{Background}

Complicated diverticular disease is defined as diverticulitis with associated abscess, phlegmon, fistula, stricture or obstruction, bleeding, or perforation [1-3]. Hinchey's classification of acute diverticulitis is including a phlegmon (stage Ia), localized abscesses (stages Ib and II), free perforation with purulent (stage III) or feculent peritonitis (stage IV) [4]. Management of the diverticular disease of the colon has seen progressive success owing to the advances of the diagnostic methods, intensive care settings, minimal access techniques and surgical experience. While there is little debate about the best treatment for mild episodes and/or very severe episodes, uncertainty persists about the optimal management for intermediate stages (Ib and II) [4].

Many studies reported variable rates of mortality and morbidities for patients presented with complicated diverticulitis. The morbidity could reach $44 \%$ [3] while the mortality rates range from as low as $1 \%$ to $16.7 \%[5,6]$. More serious colonic perforation with generalized fecal peritonitis is associated with a mortality of over $50 \%$ in most series [7]. Mortality is found to be accurately evaluated by Colorectal-Physiologic and Operative Severity Score for the enUmeration of Mortality and morbidity (POSSUM) [8].

Because of the high rates of morbidities and mortality, some authors advise prophylactic resection of the affected colonic segment depending on the outcomes and followup of people who had recurrent episodes of diverticulitis [9-12]

The aim of this study is to evaluate the outcomes of management of complicated diverticular disease of the colon in a district NHS hospital and to explore the current strategies of its treatment.

\section{Methods}

This is a retrospective study of 110 patients who have been admitted to the surgical ward of Princess royal university hospital/Kent between May 2002 and November 2006 with diagnosis of complicated diverticular disease. The spectrum of clinical picture was ranged from stage 1-4 according to Hinchey's classification.

A proforma of patients' details, mode of presentation, clinical findings, radiographic and laboratory findings, preoperative co-morbidities, type of complicated diverticulitis, operative intervention, morbidity, mortality, length of stay, operative or conservative management outcomes, intensive care admission and the follow up were recorded from the patients' case notes.
The exclusion criteria included patients who diagnosed with other bowel pathologies such as cancer, inflammatory bowel disease and mechanical obstruction due to other causes.

\section{The criteria for diagnosis and classification}

The diagnosis of the stage of complicated diverticulitis (Hinchey's classification) depended on the history, examination, laboratory findings, imaging (ultrasound \&CT scan) and colonoscopy.

The outcomes were specified using statistical analysis. The statistical significance was considered at $(P<0.05)$.

\section{Results \\ Patients' demography}

The mean age of the patients was 72.76 years (range 3987 years). Thirty-one men $(28.18 \%)$ and seventy-nine women $(71.81 \%)$. Male: female ratio was 1:2.5.

Forty-one (37.27\%) patients had one or more episodes of diverticulitis.

\section{History of diverticular disease}

About $20.90 \%$ of patients had one episode of diverticular disease. Forty-one patients (37.27\%) had two or more episodes of diverticulitis while $41.8 \%$ of patients had no history of diverticular disease.

\section{Co-morbidity}

Sixty-seven patients $(60.90 \%)$ had one or more co-morbidities. Cardiovascular disease is the commonest co-morbidity (62 patients-56.36\%). Eight diabetic patients $(7.27 \%), 28(25.45 \%)$ patients with connective tissue and vascular disease and twelve patients $(10.90 \%)$ had different co-morbidities.

\section{Clinical findings}

Phlegmon was the commonest presentation $(31.81 \%$, no $=35)$ followed by perforation $(30.90 \%$, no $=34)$, bleeding, stricture and fistula (See figure 1)

Eighty-six percent of patients were presented with acute abdominal pain while rectal bleeding was the main symptom in $14 \%$. Constipation and erratic bowel habit were the commonest chronic symptoms. Generalized tenderness was reported in 72 patients (65.45\%) while left iliac fossa tenderness was reported in 38 patients $(34.54 \%)$. Leukocytosis was reported in 58 patients $(52.72 \%)$. Sigmoid colon was the commonest site for complicated diverticultis in $91 \%$. Other sites in order of frequency were descending colon, transverse colon, ascending colon and the ceacum. 


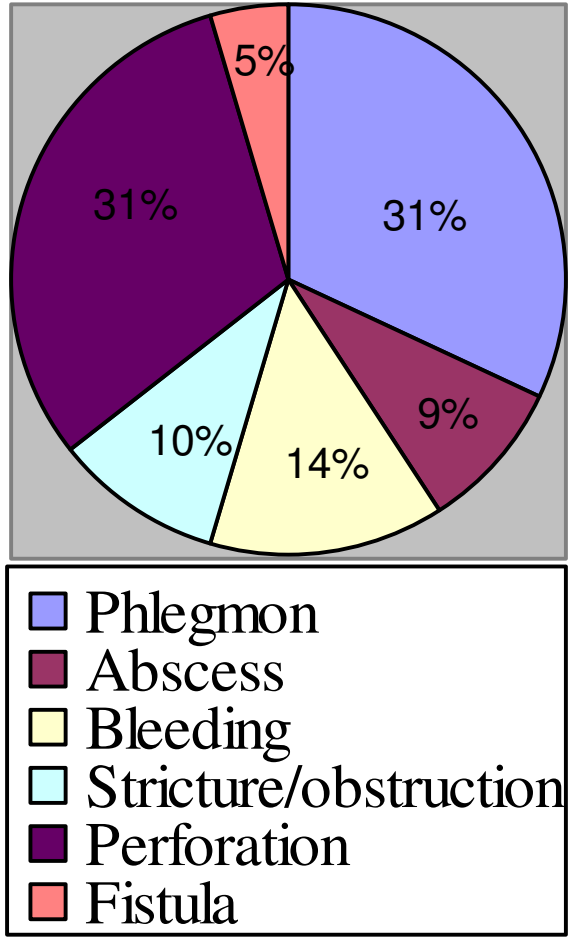

Figure I

Presentation of complicated diverticular disease.

\section{Surgical treatment}

The mean waiting time from the admission until the start of operative intervention was 20.57 hours (range 4-96 hours). Operative intervention was reported in 57 (51.81\%) patients. Hartman's procedure was performed in $32(56.14 \%)$, sigmoid colectomy and ileostomy in $15(26.30 \%)$ and proximal colostomy in $5(8.77 \%)$ patients.

Segmental resection and division of the fistula was performed for 5 (8.77\%) patients while percutaneous drainage was performed in $10(9.09 \%)$ patients with pericolic abscesses. Seven $(6.36 \%)$ patients who were presented primarily with phlegmon and bleeding underwent laparotomy because they were progressed to a worse stage during hospitalization while one of them developed perforation following colonoscopy.

\section{Conservative treatment}

Fifty-three (48.18\%) Patients were treated by intravenous fluids, analgesia, blood and antibiotics and showed an excellent response.

\section{Intensive care unit ICU}

Four $(7.01 \%)$ patients were admitted to ICU before operation while $25(43.85 \%)$ patients were admitted postoperatively. The mean ICU length of stay was 7.36 days (range 1-28 days)

\section{Histopathology}

Perforated diverticular disease was confirmed microscopically in $15(44.11 \%)$ out of 34 patients underwent emergency surgery for perforated diverticular disease. The length of the resected colon ranged from $8-93 \mathrm{~cm}$ with average of $17.59 \mathrm{~cm}$. Diverticular disease was confirmed in all resected specimens.

\section{Morbidity}

Fifty-four postoperative complications were reported with overall morbidity of $49.09 \%$. Respiratory complications $(22.22 \%)$ was the commonest morbidity followed by cardiac $(16.66 \%)$ and wound complications (14.81\%).(See table 1$)$.

\section{Mortality}

Overall mortality of this cohort was $14.53 \%$. Twelve $(10.90 \%)$ patients with perforation died (one intra-operative death, 8 post-operative deaths and 3 deaths for nonoperative treatment). Another 4 (3.63\%) patients died during follow up because of other reasons.

\section{History of diverticular disease}

Twenty-three $(20.90 \%)$ patients had a history of one episode of diverticular disease while forty-one (37.27\%) patients had two or more episodes. Fifty-seven (41.81\%) patients reported with complicated diverticulitis as their first presentation. (See figure 2)

Table I: Morbidity

\begin{tabular}{lcc}
\hline Complications & No & $\%$ \\
\hline lleus & 3 & 05.55 \\
Wound complications & 8 & 14.81 \\
Burst abdomen & 1 & 01.85 \\
Necrosis of the stoma & 1 & 01.85 \\
Pelvic abscess & 1 & 01.85 \\
Septicemia & 3 & 05.55 \\
Fistula & 2 & 03.70 \\
Incisional hernia & 4 & 07.40 \\
Renal & 5 & 09.25 \\
cardiac & 9 & 16.66 \\
Respiratory & 12 & 22.22 \\
\hline Total & 54 & 100 \\
\hline
\end{tabular}




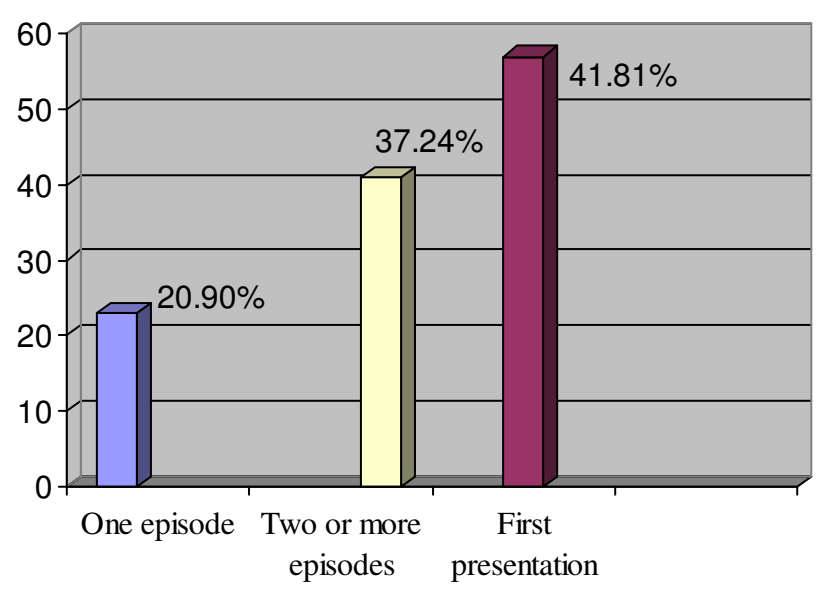

Figure 2

History of diverticular disease.

\section{Hospital stay}

The mean hospital stay was 16.40 days (range 2-61 days). Long stay was associated with perforated diverticulitis and postoperative morbidity. $(p<0.05)$

\section{Discussion}

Diverticular disease of the colon is a common problem in developed countries with its prevalence increasing with age, varying from $<10 \%$ in those $<40$ years of age, to an estimated $50-66 \%$ of patients $>80$ years of age [13]. The major factor in the development of diverticulosis is lack of adequate fiber intake $[14,15]$. A quarter of patients with diverticulitis will develop potentially life-threatening complications including bleeding, perforation, fistulae, obstruction or stricture [16].

Fifty-seven patients of our series were subjected to emergency surgical treatment (See table 2). This included patients with perforation, peritonitis, fistula, obstruction and strictures. Hartman's operation was performed in about $56 \%$ of patients who required surgery. This is consistent with other studies, which suggest Hartman's as a safe and effective procedure especially in emergency [1719]. Patients who presented with bleeding and phlegmon

Table 2: Type of operation

\begin{tabular}{lll}
\hline Type of operation & No & $\%$ \\
\hline Hartman's procedure & 32 & 56.13 \\
Sigmoid colectomy and ileostomy & 15 & 26.30 \\
Diversion only & 05 & 08.77 \\
Segmental resection and division of the fistula & 05 & 08.77 \\
\hline Total & 57 & 100 \\
\hline
\end{tabular}

were treated conservatively with intravenous fluids, blood, and optimization of coagulation profile and showed good primary response. However, seven (6.36\%) of these patients who were presented primarily with phlegmon and bleeding underwent laparotomy because they were progressed to a worse stage during hospitalization while one of them developed perforation following colonoscopy.

The overall complication rate following surgical and conservative management in our series was $49.09 \%$ (54 complications). This was less than other series, which reported a higher morbidity rate [20]. Non-surgical respiratory and cardiac complications were the commonest morbidity while wound complications were the commonest surgical morbidity (See table 1 ). The preoperative co morbidity of our series was $60.90 \%$. The presence of such co morbidities, especially older age, collagen-vascular disease, pulmonary disease, and cardiovascular disease, were all found to significantly increase the risk of development of post surgical complications[21].

The association between high morbidity and perforated diverticultis was confirmed in our study however, no significant association between morbidity and other forms of complicated diverticulitis was found.

Only $21 \%$ of perforated diverticulitis had a previous history of diverticular disease while $58.2 \%$ of other less severe forms such as phlegmon, bleeding and localized pericolic abscess had such positive history. This statistically significant association $(P$ value $=0.00)$ was also confirmed in other studies [22].

The rate of progression of diverticular disease to complicated diverticulitis is varied. After one episode of diverticulitis, one-third of patients have recurrent symptoms; after a second episode, a further third have a subsequent episode while perforation is commonest during the first episode of acute diverticulitis [23]. An acute complicated presentation of the disease occurs in a minority of patients range from $15-25 \%$ [24-26].

Variable mortality rate was reported in literature and ranged from $4-16 \%$ while high mortality figure of $50 \%$ was confirmed in cases of perforation with generalized fecal peritonitis [27-31]. Our perioperative mortality rate was $10.90 \%$. The majority of deaths associated with perforated diverticulitis, which was reported in $66.66 \%$ while pericolic abscess was confirmed in $33.33 \%$ of deaths (See table 3 ). Four patients (3.63\%) who were diagnosed with perforated diverticulitis were very high-risk patients because of age and co morbidity and a decision was made to treat them conservatively. Three $(2.72 \%)$ of them died while one patient responded to this approach. Another 
Table 3: Risk factors for perioperative mortality

\begin{tabular}{|c|c|c|c|c|c|c|c|c|c|c|c|c|}
\hline \multirow[b]{2}{*}{ Variable } & \multicolumn{12}{|c|}{ Patients } \\
\hline & 1 & 2 & 3 & 4 & 5 & 6 & 7 & 8 & 9 & 10 & 11 & 12 \\
\hline Cardiovascular & & & $*$ & $*$ & $*$ & & $*$ & $*$ & $*$ & $*$ & $*$ & * \\
\hline Respiratory & & $*$ & & & & $*$ & & & & & $*$ & \\
\hline Connective tissue disorder & & & & & & & & $*$ & & & $*$ & \\
\hline Diabetes & & & & & & & & & $*$ & & & \\
\hline Immune suppression & $*$ & & & & & & & $*$ & & & & \\
\hline Renal & & & & & $*$ & $*$ & & & & $*$ & & \\
\hline Perforation & $*$ & $*$ & $*$ & $*$ & $*$ & & $*$ & & & $*$ & $*$ & \\
\hline Abscess & & & & & & $*$ & & $*$ & $*$ & & & $*$ \\
\hline \multicolumn{13}{|l|}{ Bleeding } \\
\hline \multicolumn{13}{|l|}{ Fistula } \\
\hline \multicolumn{13}{|l|}{ Obstruction/stricture } \\
\hline \multicolumn{13}{|l|}{ Phlegmon } \\
\hline Age (year) & 86 & 80 & 60 & 80 & 83 & 85 & 86 & 65 & 84 & 82 & 77 & 84 \\
\hline Sex:F = Female, $M=$ Male & $\mathrm{F}$ & $\mathrm{F}$ & $\mathrm{F}$ & $\mathrm{F}$ & $\mathrm{F}$ & $\mathrm{F}$ & $\mathrm{F}$ & $\mathrm{F}$ & $\mathrm{F}$ & $M$ & $\mathrm{~F}$ & $\mathrm{~F}$ \\
\hline
\end{tabular}

four $(3.63 \%)$ patients died because of other pathologies making the overall mortality figure of $14.53 \%$. The mean age of deaths was 79.33 years and majority were women $(91.16 \%)$.

Surgery for acute complications of diverticular disease of the sigmoid colon carries significant rates of morbidity and mortality, the latter of which occurs predominantly in cases of severe co morbidity. Therefore, postoperative mortality and morbidity are largely driven by patientrelated factors [32,33].

There are no clear guidelines for the indication of elective surgery in sigmoid diverticular disease although in patients with recurrent diverticulitis or with fistulae, the long-term results of surgery are satisfactory [34]. Moreover, precise criteria, which indicate elective or prophylactic surgery in patients with diverticular disease of the colon, are anatomical deformity of the sigmoid, including stenosis and fistulae, recurrent acute diverticulitis, prior diverticulitis with perforation and recurrent gastrointestinal bleeding. Many authors accepted these criteria [35-39].

Some authors suggest laparoscopic lavage and drainage of perforated acute diverticulitis as a promising alternative to more radical procedures [40]. Furthermore, minimal access surgery as elective treatment of sigmoid diverticular disease may be associated with reduced postoperative morbidity and hospital stay. It is increasingly replacing open resection as standard surgery for recurrent and complicated diverticulitis at certain centers [41-44].

Identification of patients who are at risk to develop complicated diverticulitis especially perforation, is very important to reduce mortality and morbidity. In our study cardiovascular, connective tissue disorders and diabetes were the commonest co morbidities associated with complicated diverticulitis. The factors that associated with mortality following complicated diverticulitis in our series were age, sex (female patient), cardiovascular, respiratory problems and immune suppression. Perforation and pericolic abscess were also risk factors for mortality.

These parameters and their effects, which have been confirmed in literatures, should be taken in consideration during management of complicated diverticular disease [45-47].

The risk factors for perioperative mortality in our series included the age (about $75 \%$ of patients were above 80 year), female patients ( $91.6 \%$ were female), cardiovascular disease (75\%), Renal and respiratory disease (25\%), Immune suppression and diabetes $(16 \%$ and $08 \%$ respectively) (see table 3 ). Therefore, to reduce future mortality we suggest that prophylactic segmental colonic resection should be advised especially for female patients with recurrent episodes of diverticulitis, who are less than 70 year old, who have associated cardiovascular, respiratory or renal co morbidities. Severity of episode, without doubt is another inclusion criterion. This is generally consistent with the principle that prophylactic segmental colonic resection must be based on a balance assessment of risk factors including age, severity of attacks and their recurrence $[48,49]$.

As acute surgical emergency, acute complicated diverticulitis resembles acute appendicitis to a large extent except for certain features. The similarity included also the high morbidity and mortality associated with these two conditions. Although major advances in the management of 
complicated diverticulitis have been well documented and currently widely practiced, however the overall management plan included prophylactic resection, is still under continuous evolution and less radically treated in comparison to the acute appendicitis. We think that acute diverticulitis and its complications should be treated effectively, as acute appendicitis is treated. Therefore, all patients with acute complicated diverticulitis should be followed-up and certain group of these patients has to be advised for further surgical intervention. This will need more clarification and definition of the indication criteria for prophylactic resection. According to our findings, these criteria should include the age limit, sex (females), and associated co-morbidities.

Our study has defined important risk factors for mortality, and therefore we are advising a more radical approach for management of this disease. However, further larger study is suggested to confirm our conclusions.

\section{Conclusion}

Complicated diverticulitis carries a significant mortality and morbidity. Identification of high-risk patients to develop complications is important to reduce mortality and morbidity. Preoperative co-morbidities are the major influencing factor for peri-operative mortality and morbidity. Emergency Hartman's operation is the procedure of choice to treat majority of perforated diverticulitis. Prophylactic segmental colonic resection may be suggested for selected group of patients.

\section{Competing interests}

The author(s) declare that they have no competing interests.

\section{Authors' contributions}

A Hussain wrote the article, participated in the sequence alignment and drafted the manuscript. G Subhas carried out the data collection. H Mahmood participated in the sequence alignment, the design of the study and performed the statistical analysis. S El-hsani conceived of the study, and participated in its design and coordination and helped to draft the manuscript. All authors read and approved the final manuscript.

\section{References}

I. Berry AR, Turner WH, Mortensen NJ, Kettlewell MG: Emergency surgery for complicated diverticular disease: a five-year experience. Dis Colon Rectum 1989, 32:849-854.

2. Nagorney DM, Adson MA, Pemberton JH: Sigmoid diverticulitis with perforation and generalized peritonitis. Dis Colon Rectum 1985, 28:71-75.

3. Schwesinger WH, Page CP, Gaskill HV 3rd, Steward RM, Chopra S, Strodel WE, Sirinek KR: Operative management of diverticular emergencies. Strategies and outcomes. Arch Surg 2000 135:558-563.

4. Kaiser AM, Jiang JK, Lake JP, Ault G, Artinyan A, Gonzalez-Ruiz C, Essani R, Beart RW Jr: The management of complicated diver- ticulitis and the role of computed tomography. Am J Gastroenterol 2005, 100:910-7.

5. Piccolini M, Francia L, Rosa C, Biandrate F, Campagnoni AP, Pandolfi U: Complicated diverticular disease of the colon: 5 years' experience in a provincial hospital. Chir ltal 2007, 59:197-206.

6. Oomen JL, Engel AF, Cuesta MA: Mortality after acute surgery for complications of diverticular disease of the sigmoid colon is almost exclusively due to patient related factors. Colorectal Dis 2006, 8: I 12-9.

7. Scholefield JH, Wyman A, Rogers K: Management of generalized faecal peritonitis - can we do better. J $R$ Soc Med I99I, 84:664-6.

8. Constantinides VA, Tekkis PP, Senapati A: Association of Coloproctology of Great Britain and Ireland. Comparison of POSSUM scoring systems and the surgical risk scale in patients undergoing surgery for complicated diverticular disease. Dis Colon Rectum 2006, 49:1322-31.

9. Rinas $U$, Adamek HE: Diverticulitis and diverticulosis. $M M W$ Fortschr Med 2006, 1 48:37-4I.

10. Hansen O, Zarras K, Graupe F, Dellana M, Stock W: Surgical treatment of diverticulitis of the large intestine - a plea for early elective resection. Zentralbl Chir 1996, I2 1:190-200.

II. Bouillot JL, Berthou JC, Champault G, Meyer C, Arnaud JP, Samama G, Collet D, Bressler P, Gainant A, Delaitre B: Elective laparoscopic colonic resection for diverticular disease: results of a multicenter study in 179 patients. Surg Endosc 2002, 16:1320-3.

12. Griffen WO Jr: Management of the acute complications of diverticular disease: acute perforation of colonic diverticula. Dis Colon Rectum 1976, 19:293-295.

13. Tursi A: Acute diverticulitis of the colon - current medical therapeutic management. Expert Opin Pharmacother 2004, 5:55-9.

14. Bogardus ST Jr: What do we know about diverticular disease? A brief overview. I Clin Gastroenterol 2006, 40:SI08-II.

15. Korzenik JR: Case closed? Diverticulitis: epidemiology and fiber. I Clin Gastroenterol 2006, 40:SI I2-6.

16. Kang JY, Melville D, Maxwell JD: Epidemiology and management of diverticular disease of the colon. Drugs Aging 2004, 2 I:2 I I-28.

17. Cavallaro A, Loschiavo V, Potenza AE, Modugno P, Fabbri MC, Revelli L, Colli R: Diverticular disease: complications and treatment. Chir Ital 2002, 54:693-8.

18. Rohr S, Thiry CL, Sadok H, de Manzini N, Hollender LF, Meyer C: Complicated colonic diverticulosis. Changes in treatment and results over 22 years. Presse Med 1994, 14:834-8.

19. Röthlin M, Rietschi G, Largiadèr F: Value of Hartmann's operation as an emergency intervention in sigmoid diverticulitis. Swiss Surg 1997, 3:107-II.

20. Takahashi-Monroy T, Velasco L, Morales-Olivera JM: Morbi-mortality of Hartmann's reversal procedure. Cir Cir 2006, 74:329-33.

21. Chapman J, Davies M, Wolff B, Dozois E, Tessier D, Harrington J, Larson $D$ : Complicated diverticulitis: is it time to rethink the rules? Ann Surg 2005, 242:576-8I.

22. Salem TA, Molloy RG, O'Dwyer PJ: Prospective study on the management of patients with complicated diverticular disease. Colorectal Dis 2006, 8: 173-6.

23. Janes $\mathrm{S}$, Meagher $\mathrm{A}$, Frizelle FA: Elective surgery after acute diverticulitis. Br J Surg 2005, 92: I33-42.

24. Hackford AW, Veidenheimer MC: Diverticular disease of the colon. Current concepts and management. Surg Clin North Am 1985, 65:347-63.

25. Alberti A, Dattola P, Parisi A, Maccarone P, Basile M: Role of ultrasonographic imaging in the surgical management of acute diverticulitis of the colon. Chir Ital 2002, 54:71-5.

26. Anton CR, Balan G: Colonic diverticulosis - current issues in etiopathogenesis, diagnosis and treatment. Rev Med Chir Soc Med Nat lasi 2004, 108:269-74.

27. Constantinides VA, Tekkis PP, Senapati A: Association of Coloproctology of Great Britain Ireland. Prospective multicentre evaluation of adverse outcomes following treatment for complicated diverticular disease. Br J Surg 2006, 93:I503-13.

28. Porzio S, Rossi S, Lombardi V, Milito G: Surgical treatment of complicated diverticular disease of the colon. Chir Ital 1999, 5I:199-205.

29. Le Néel JC, Denimal F, Letessier E, Bernard P, Jurczak F, Armstrong O: Complicated colonic diverticulosis. Results of surgical 
treatment between $198 \mathrm{I}$ and 1998 in 370 patients. Ann Chir 2000, I 25:334-9.

30. Ressetta G, Simeth C, Ziza F, La Bruna D, Balani A: Colonic diverticulosis complicated with perforation. Analysis of several prognosis variables and criteria for emergency surgery. Ann Ital Chir 1998, 69:63-70.

31. Khan AL, Ah-See AK, Crofts TJ, Heys SD, Eremin O: Surgical management of the septic complications of diverticular disease. Ann R Coll Surg Engl 1995, 77:16-20.

32. Comparato G, Pilotto A, Franzè A, Franceschi M, Di Mario F: Diverticular disease in the elderly. Dig Dis 2007, 25:15I-9.

33. Schoetz D): Diverticular disease of the colon: a century old problem. Dis Colon Rectum 1999, 42:703-709.

34. Bannura G, Contreras J, Melo C, Barrera A, Soto D, Mansilla J: Indications and long term results of elective surgery for sigmoid diverticular disease. Rev Med Chil 2005, 133:1037-42.

35. Bottinelli $A$, López $F$, Rahmer A, Zúñiga A: Diverticular disease of the colon, the indications for and results of elective surgical treatment]. Rev Med Chil 1990, I I 8:1206-10.

36. Le Néel JC, Guiberteau B, Borde L, Sartre JY, Bourseau JC: What is? the role of elective surgery in diverticular sigmoiditis?]. Chirurgie 1992, I I 8:457-62.

37. Ferulano GP, Dilillo S, D'Ambra M, Saviano C, Brunaccino R, Lionetti $R$, Fico D: Timing and results of the surgical treatment of the diverticular disease of the colon. Ann Ital Chir 2006, 77:497-502.

38. Fornaro R, Canaletti M, Terrizzi A, Davini MD, Sticchi C, Stabilini C, Moraglia E, Picori E, Larghero GC, Giannetta E: Surgery for complicated colonic diverticulitis. Our experience. G Chir 2005, 26: 143-52.

39. Häring RU, Salm R: Sigmoid diverticulitis - indications for surgery and choice of procedure. MMW Fortschr Med 2003 , 145:32-5.

40. Taylor CJ, Layani L, Ghusn MA, White SI: Perforated diverticulitis managed by laparoscopic lavage. ANZ J Surg 2006, 76:962-5.

4I. Alves A, Panis Y, Slim K, Heyd B, Kwiatkowski F, Mantion G: Association Français de Chirurgie. French multicentre prospective observational study of laparoscopic versus open colectomy for sigmoid diverticular disease. Br J Surg 2005, 92: 1520-5.

42. Schwandner O, Farke S, Fischer F, Eckmann C, Schiedeck TH, Bruch HP: Laparoscopic colectomy for recurrent and complicated diverticulitis: a prospective study of 396 patients. Langenbecks Arch Surg 2004, 389:97-103.

43. Vargas HD, Ramirez RT, Hoffman GC, Hubbard GW, Gould RJ, Wohlgemuth SD, Ruffin WK, Hatter JE, Kolm P: Defining the role of laparoscopic-assisted sigmoid colectomy for diverticulitis. Dis Colon Rectum 2000, 43:1726-31.

44. Senagore AJ: Laparoscopic sigmoid colectomy for diverticular disease. Surg Clin North Am 2005, 85: 19-24.

45. Lederman ED, Conti DJ, Lempert N, Singh TP, Lee EC: Complicated diverticulitis following renal transplantation. Dis Colon Rectum 1998, 41:613-618.

46. Moreno AM, Wille-Jørgensen P: Long-term outcome in $\mathbf{4 4 5}$ patients after diagnosis of diverticular disease. Colorectal Dis 2007, 9:464-8.

47. Oomen JL, Engel AF, Cuesta MA: Mortality after acute surgery for complications of diverticular disease of the sigmoid colon is almost exclusively due to patient related factors. Colorectal Dis 2006, 8: I I 2-9.

48. Mutter D, Jamali F, Marescaux J: Surgical treatment of acute sigmoiditis. J Chir (Paris) 2000, 137:16-20.

49. Millat B, Guillon F: Treatment of acute sigmoid diverticulitis and development. Rev Prat 1995, 45:963-7.

\section{Publish with Biomed Central and every} scientist can read your work free of charge

"BioMed Central will be the most significant development for disseminating the results of biomedical research in our lifetime. "

Sir Paul Nurse, Cancer Research UK

Your research papers will be:

- available free of charge to the entire biomedical community

- peer reviewed and published immediately upon acceptance

- cited in PubMed and archived on PubMed Central

- yours - you keep the copyright
BioMedcentral 